\title{
Resposta fisiológica de sementes de chia e linhaça ao estresse hídrico
}

\author{
Raquel Stefanello, Bruna Boucinha Viana \& Luiz Augusto Salles das Neves
}

Universidade Federal de Santa Maria, Departamento de Biologia, Av. Roraima, 1000, CEP 97105-900, Santa Maria, RS. raquelstefanello@yahoo.com.br

RESUMO - Estudos sobre relações hídricas são importantes para o conhecimento da germinação das sementes. O objetivo deste estudo foi avaliar a resposta fisiológica (germinação) das sementes de chia e linhaça ao estresse hídrico. As sementes foram colocadas sobre papel embebido em solução aquosa de polietileno glicol em diferentes potenciais osmóticos. Foram avaliados a percentagem de germinação, primeira contagem e índice de velocidade de germinação. A redução do potencial osmótico do substrato promoveu decréscimo significativo na germinação das sementes de chia e linhaça. Conclui-se que as sementes destas espécies não toleram potenciais osmóticos iguais ou inferiores a - $0,15 \mathrm{MPa}$, sendo possível o seu cultivo em áreas agrícolas nas concentrações acima destes potenciais.

Palavras-chave: Linum usitatissimum L., polietileno glicol, Salvia hispanica L.

\begin{abstract}
Physiological response of chia seeds and linseed to water stress. Studies on water resources are important to understand seed germination. The objective of this study was to evaluate the physiological (germination) response of chia seeds and linseed to water stress. The seeds were placed on paper soaked in solutions of polyethylene glycol in different osmotic potentials. Percentage of germination, first germination count, and germination speed index were evaluated. The reduction of the osmotic potential of the substrate promoted a significant decrease in the germination and vigor of the chia seeds and linseed. In conclusion, seeds of these species are not able to tolerate osmotic potentials equal to or lower than $-0.15 \mathrm{MPa}$, being making possible its cultivation areas with concentrations above osmotic potentials.
\end{abstract}

Keywords: Linum usitatissimum L., polyethylene glycol, Salvia hispanica L.

\section{INTRODUÇÃO}

Para que as sementes germinem é necessário que existam condições favoráveis de oxigênio, luz, temperatura e disponibilidade de água (Carvalho \& Nakagawa 2012). A água é fundamental para o início da germinação, uma vez que a semente deve atingir determinado conteúdo de água para germinar. As sementes respondem diferentemente à quantidade de água no substrato sendo que quando em excesso pode tanto promover como inibir a germinação (Cardoso 2012).

Estudos sobre relações hídricas são importantes para o conhecimento do processo germinativo das sementes. Alguns trabalhos têm sido conduzidos utilizando soluções de polietileno glicol (PEG 6000) com diferentes potenciais osmóticos, onde as sementes são colocadas para germinar, procurando simular condições de baixa disponibilidade de água no solo (Almeida et al. 2014, Gordin et al. 2015, Lavezo et al. 2015, Naim \& Ahmed 2015, Shen et al. 2015). De maneira geral, estes autores sugerem que a redução do potencial osmótico do substrato afeta negativamente a germinação das sementes de acordo com a espécie e a concentração do soluto utilizado.

As sementes de chia e linhaça estão sujeitas às condições de estresse hídrico que limitam o seu desenvolvimento e suas chances de sobrevivência. Considerando benéfico o conhecimento das espécies capazes de suportar uma determinada condição de estresse, tanto para a caracterização da cultura, quanto para auxiliar na adequada recomendação para o plantio nestas situações, objetivou-se avaliar a resposta fisiológica das sementes de chia e linhaça ao estresse hídrico.

\section{MATERIAL E MÉTODOS}

Para as avaliações do efeito do estresse hídrico na germinação de sementes de chia (Salvia hispanica) e linhaça (Linum usitatissimum), utilizou-se solução aquosa de polietileno glicol (PEG 6000) nas concentrações correspondentes a zero; $-0,05 ;-0,10 ;-0,15 ;-0,20 ;-0,25$; $-0,30 \mathrm{MPa}$. O nível zero correspondeu à testemunha, onde se utilizou água destilada. A quantidade de PEG necessária para obtenção dos potenciais osmóticos foi obtida em Stefanello et al. (2008).

O potencial fisiológico das sementes foi avaliado em câmara B.O.D, com regime de $8 \mathrm{~h}$ de luz e 16 h sem luz, através do teste de germinação realizado em caixas plásticas transparentes. As sementes foram acondicionadas sobre três folhas de papel-filtro umedecidas com água destilada 
no tratamento controle ( $0 \mathrm{MPa})$ e nas respectivas soluções de PEG 6000 na proporção de 2,5 vezes o peso seco do papel. Após a semeadura, as caixas plásticas foram mantidas na temperatura de $20^{\circ} \mathrm{C}$, sendo a primeira contagem de germinação realizada após seis (linhaça) e sete dias (chia). A última contagem de germinação foi realizada após dez (linhaça) e 14 dias (chia). Foram avaliadas as plântulas normais, sendo os resultados expressos em percentagem de plântulas normais (Brasil 2009). Para avaliação do índice de velocidade de germinação (IVG), as contagens das sementes germinadas foram efetuadas diariamente, no mesmo horário utilizando-se como critério de germinação, a protrusão da raiz primária. $\mathrm{O}$ índice de velocidade de germinação foi calculado empregando-se a fórmula de (Maguire 1962).

$\mathrm{O}$ delineamento experimental utilizado foi o inteiramente casualizado, onde os tratamentos constituíramse das diferentes concentrações de polietileno glicol (PEG 6000), com seis repetições de 50 sementes. Os dados foram submetidos à análise de variância pelo teste $\mathrm{F}$ e, quando constatado efeito significativo, foi efetuada a análise de regressão pelo programa Sisvar.

\section{RESULTADOS E DISCUSSÃO}

Através da análise dos dados de germinação das sementes de chia e linhaça observou-se diferença em função dos potenciais osmóticos da solução (Fig. 1). $\mathrm{Na}$ ausência do polietileno glicol, as sementes de chia apresentaram em média germinação de $88 \%$, verificandose uma redução acentuada nas demais concentrações de PEG 6000, alcançando valores inferiores a 50\% a partir do potencial - $0,15 \mathrm{MPa}$. Por outro lado, nas sementes de linhaça a germinação média foi de $83 \%$ na ausência de PEG e atingindo $40 \%$ de germinação no menor potencial osmótico utilizado (-0,30 MPa).

De acordo com Ghaderi-Far et al. (2010), a redução do potencial hídrico, associada ao efeito tóxico dos sais presentes no solo, como por exemplo o cloreto de sódio, interfere inicialmente no processo de absorção de água pelas sementes, o que pode influenciar na germinação, no vigor das plântulas e, consequentemente, no desenvolvimento normal das plantas. $\mathrm{O}$ estresse hídrico geralmente atua diminuindo a velocidade e a porcentagem de germinação das sementes, sendo que para cada espécie existe um valor de potencial hídrico crítico, abaixo do qual a germinação não ocorre (Bewley et al. 2013).

Os resultados deste estudo corroboram com os realizados em Guizotia abyssinica Cass. (Gordin et al. 2015), Petiveria alliacea L. (Lavezo et al. 2015), Cicer arietinum L. (Naim \& Ahmed 2015), Jatropha curcas L. (Pereira \& Lopes 2011) e Euryodendron excelsum H. T. Chang (Shen et al. 2015) verificando-se redução na porcentagem de germinação, com o aumento da concentração de polietileno glicol. Adicionalmente, o potencial hídrico a partir de $-0,6 \mathrm{MPa}$ torna-se uma condição limitante na germinação e formação de plântulas normais de Amburana cearensis (Allemão) A.C. Smith (Almeida et al. 2014).
Nas duas espécies estudadas, verificou-se redução da percentagem de plântulas normais e da velocidade de germinação com o decréscimo do potencial hídrico da solução (Fig. 1). Além disso, observou-se correlação positiva entre as variáveis germinação e IVG (Tab. 1) indicando que, nas condições deste experimento, à medida que diminuiu a velocidade de germinação ocorreu decréscimo da percentagem de plântulas normais avaliadas através do teste de germinação. Outras características relevantes a serem consideradas neste estudo referem-se à ausência de plântulas normais na primeira contagem de germinação das sementes de chia abaixo do potencial
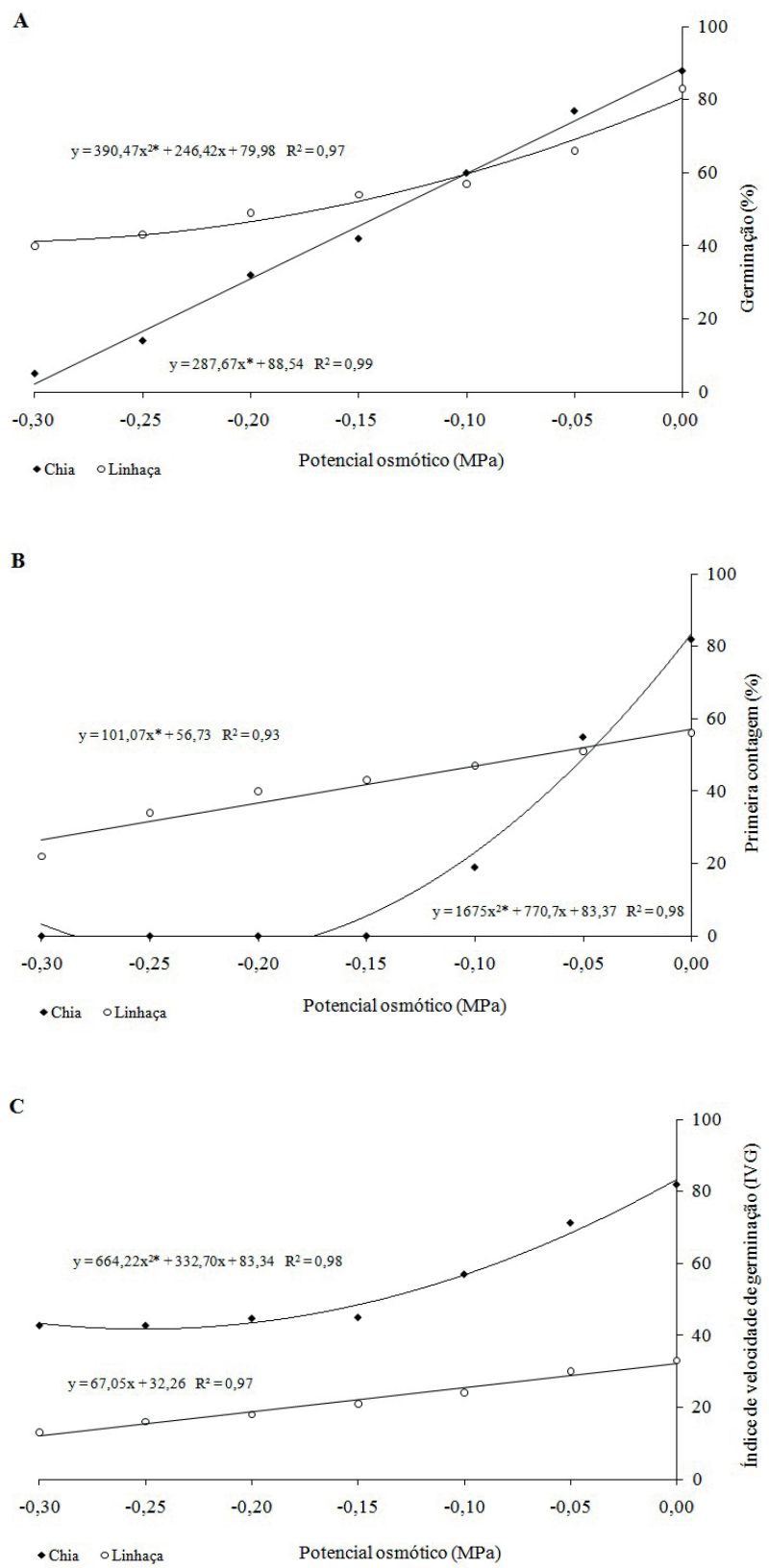

Figs. 1A-C. A. Germinação; B. primeira contagem; C. índice de velocidade de germinação de sementes de chia e linhaça submetidas a diferentes potenciais osmóticos em solução de polietileno glicol. 
Tabela 1. Coeficiente de correlação de Pearson (r) entre germinação e primeira contagem e entre germinação e índice de velocidade de germinação (IVG) em sementes de chia e linhaça submetidas a diferentes potenciais osmóticos em solução de polietileno glicol. * significativo a $5 \%$.

\begin{tabular}{llcl}
\hline Espécie & & Primeira contagem & IVG \\
\hline Chia & Germinação & $0,884^{*}$ & $0,926^{*}$ \\
Linhaça & Germinação & $0,905^{*}$ & $0,971^{*}$ \\
\hline
\end{tabular}

osmótico de - $0,15 \mathrm{MPa}$ e à baixa velocidade de germinação nas sementes de linhaça que pode ser atribuída à baixa qualidade fisiológica do lote utilizado.

Da mesma forma, Pereira \& Lopes (2011) observaram que, em sementes de pinhão-manso (Jatropha curcas L.), a redução do potencial osmótico do substrato reduziu expressivamente a germinação das sementes, bem como a velocidade de germinação e o desempenho das plântulas. De acordo com Cardoso (2012), a embebição prévia das sementes numa solução osmótica, principalmente de polietileno glicol, atua inibindo a quantidade e a velocidade de absorção de água, impedindo assim a protrusão radicular.

Utilizando outras soluções que também simulam o estresse hídrico em laboratório, Dal'maso et al. (2013) observaram que o aumento da concentração de cloreto de potássio $(\mathrm{KCl})$ reduziu o índice de velocidade de germinação, a percentagem de germinação e o crescimento de plântulas de chia. Também, Stefanello et al. (2015) utilizando soluções de cloreto de sódio $(\mathrm{NaCl})$ constataram decréscimo da germinação e do vigor das sementes de chia com a diminuição do potencial osmótico da solução.

Por fim, os resultados do teste de germinação demonstraram que a redução do potencial osmótico do substrato promoveu decréscimo significativo na germinação das sementes de chia e linhaça. Conclui-se que as sementes destas espécies não toleram potenciais osmóticos iguais ou inferiores a - $0,15 \mathrm{MPa}$, sendo possível o seu cultivo em áreas agrícolas nas concentrações acima destes potenciais. Estas informações podem auxiliar no entendimento da distribuição geográfica destas espécies e no papel que a escassez de água desempenha na germinação de suas sementes.

\section{REFERÊNCIAS}

Almeida, J.P.N., Pinheiro, C.L., Lessa, B.F.T., Gomes, F.M. \& Medeiros Filho, S. 2014. Estresse hídrico e massa de sementes na germinação e crescimento de plântulas de Amburana cearensis (Allemão) A.C. Smith. Revista Ciência Agronômica 45(4):777-787.

Bewley, J.D., Bradford, K.J., Hilhorst, W.M. \& Nonogaki, H. 2013. Seeds: physiology of development, germination and dormancy. Springer, London. 392p.

Brasil. 2009. Ministério da Agricultura, Pecuária e Abastecimento. Regras para análise de sementes. Ministério da Agricultura, Pecuária e Abastecimento. Secretaria de Defesa Agropecuária. Brasília. 399 p.

Cardoso, V.J.M. 2012. Germinação. In Fisiologia vegetal (G.B. Kerbauy, ed.). Guanabara Koogan, Rio de Janeiro, p. 386-408.

Carvalho, N.M. \& Nakagawa, J. 2012. Sementes: ciência, tecnologia e produção. Fundação de Apoio a Pesquisa, Ensino e Extensão, Jaboticabal. 590p.

Dal'maso, E.G., Casarin, J., Costa, P.F., Cavalheiro, D.B., Santos, B.S. \& Guimarães, V.F. 2013. Salinidade na germinação e desenvolvimento inicial de sementes de chia. Cultivando o saber 6(3):26-39.

Ghaderi-Far, F; Gherekhloo, J. \& Alimagham, M. 2010. Influence of environmental factors on seed germination and seedling emergence of yellow sweet clover (Melilotus officinalis). Planta Daninha 28(3):436-469

Gordin, C.R.B., Scalon, S.P.Q. \& Masetto, T.E. 2015. Disponibilidade hídrica do substrato e teor de água da semente na germinação de niger. Pesquisa Agropecuária Tropical 45(3):312-318.

Lavezo, A., Braga, L.F., Batistão, A.C. \& Bonfante, L.V. 2015. Estresse osmótico na germinação de sementes de Petiveria alliacea L. Revista Brasileira de Plantas Medicinais 17(4):622-630.

Maguire, J.D. 1962. Speed of germination-aid in selection and evaluation for seedling emergence and vigor. Crop Science 2(2):176-177.

Naim, A.H. \& Ahmed, F.E. 2015. Interactive effect of temperature and water stress induced by polyethylene glycol (PEG) on germination and recovery of two chickpe (Cicer arietinum L.) cultivars. Open Access Library Journal 2:1-7.

Pereira, M. D. \& Lopes, J.C. 2011. Germinação e desenvolvimento de plântulas de pinhão manso sob condições de estresse hídrico simulado. Semina: Ciências Agrárias 32(1):1837-1842.

Shen, S., Wu, F., Yang, G., Wang, Y. \& He, S. 2015. Seed germination and seedling emergence of Euryodendron excelsum H. T. Chang: implications for species conservation and restoration. Plant Species Biology 1-6.

Stefanello, R., Abbad, M.A.B., Neves, L.A.S., Viana, B.B. 2015. Resposta fisiológica de sementes de chia (Salvia hispanica - Lamiales: Lamiaceae) ao estresse salino. Biotemas 28(4):35-39.

Stefanello, R., Garcia, D.C., Menezes, N.L. \& Castilhos, G. 2008. Efeito do estresse hídrico na germinação e no vigor de sementes de anis (Pimpinella anisum L.), funcho (Foeniculum vulgare Miller) e endro (Anethum graveolens L.). Revista Brasileira de Plantas Medicinais 10(2):68-74. 